\title{
The effects of sonic hedgehog signaling pathway components on non-small-cell lung cancer progression and clinical outcome
}

\author{
Jinwook Hwang ${ }^{1}$, Myoung Hee Kang ${ }^{2}$, Young A Yoo ${ }^{2}$, Yu Hua Quan ${ }^{3}$, Hyun Koo Kim³ ${ }^{3 *}$ Sang Cheul Oh ${ }^{2 *}$
} and Young $\mathrm{Ho} \mathrm{Choi}^{3}$

\begin{abstract}
Background: Researchers in recent studies have reported that the sonic hedgehog (Shh) signaling pathway plays a crucial role during tumorigenesis, angiogenesis and cellular differentiation. We investigated the clinical and pathological significances of the Shh pathway and of its lymphangiogenic components in non-small-cell lung cancer (NSCLC), namely, Shh, glioma-associated oncogene homolog zinc finger protein 1 (Gli1), lymphatic vessel endothelial hyaluronan receptor 1 (LYVE-1) and vascular endothelial growth factor D (VEGF-D).

Methods: The expression of Shh, Gli1, LYVE-1 and VEGF-D in primary NSCLC tissue from 40 patients was examined using immunohistochemical assays, and relationships between expression and clinicopathological data, such as age, gender, histology, tumor size, nodal stage, visceral pleural invasion, lymphatic thromboembolism, recurrence and overall survival were investigated.

Results: Of the 40 specimens examined, 25 (62.5\%), 20 (50.0\%), 11 (27.5\%) and 20 (50.0\%) were positive for Shh, Gli1, LYVE-1 or VEGF-D expression, respectively. The expression of Gli1 and LYVE-1 were significantly associated $(P=0.011)$, and Shh and LYVE-1 expression was related to visceral pleural invasion and lymphatic thromboembolism, respectively $(P<0.05)$. Shh expression levels compared on survival curves were statistically significant in univariate logrank analysis $(P=0.020)$. However, other clinicopathological factors did not reveal any statistical significance in univariate and multivariate analyses.

Conclusions: To our knowledge, this the first report of the relationship between components of the Shh signaling pathway and prognosis in NSCLC. The expression of Shh, Gli1 and LVVE-1 was found to be associated with clinicopathological factors and survival. Thus, the overexpression of the Shh signaling pathway could serve as a predictor of malignant behavior, including lymphangiogenesis, in NSCLC.
\end{abstract}

Keywords: Gli1, Hedgehog pathway, LYVE-1, NSCLC, Prognosis, Sonic hedgehog, VEGF-D

\section{Background}

Lung cancer is one of the most common causes of cancerrelated mortality worldwide [1], and, though its incidence is decreasing among men, the disease shows an increasing trend among women [2]. Air pollution and smoking are

\footnotetext{
* Correspondence: kimhyunkoo@korea.ac.kr; sachoh@korea.ac.kr

${ }^{3}$ Department of Thoracic and Cardiovascular Surgery, Korea University Guro Hospital, Korea University College of Medicine, 97 Guro-dong kil, Guro-ku, Seoul 152-703, Republic of Korea

${ }^{2}$ Division of Oncology/Hematology, Departments of Internal Medicine, Korea University Guro Hospital, Korea University College of Medicine, 97 Guro-dong kil, Guro-ku, Seoul 152-703, Republic of Korea

Full list of author information is available at the end of the article
}

well-known etiologies of lung cancer. The only curative treatment modality is complete surgical resection, but many patients have advanced disease with distant metastasis at initial presentation. In such patients, the frequency of recurrence is high after complete resection. Accordingly, the prognosis of lung cancer is dismal, with an overall 5 -year survival rate of less than $15 \%$. Owing to the minimal improvements achieved over the past 30 years, a new molecular targeting strategy is needed $[3,4]$.

The early involvement of the lymphatic system in lung cancer is a probable cause of its poor prognosis, and the presence of lymph node metastasis ( $\mathrm{N}$ station) is a 
clinically important prognostic factor that influences therapeutic strategies [5,6]. Lung cancer can spread in three ways: through the lymphatic and vascular systems and by direct invasion. In the lymphatic system, tumor cells metastasize to intrapulmonary, mediastinal or extrathoracic lymph nodes [5]. If intrapulmonary lymph node metastasis (the N1 station) is confirmed, indicating lymphatic metastasis is limited to one lung, the prognosis is better than that for mediastinal lymph node metastases (the $\mathrm{N} 2$ station), which indicates tumor cell spread to the axial lymphatic system and possible metastasis to the contralateral lung or extrathoracic organs [6]. The mechanism of early tumor spread and ease of lymphatic involvement has not been elucidated, although lymphangiogenesis has been suggested to be involved in cancer metastasis with angiogenesis [7]. Several genes are involved in lymphangiogenesis, and tumors can provoke lymphatic capillary growth by producing lymphangiogenic factors, such as the lymphatic vessel endothelial hyaluronan receptor 1 (LYVE-1) members of the vascular endothelial growth factor (VEGF) family. Furthermore, it has been shown that the activity of tumor-induced lymphangiogenesis is directly correlated with the extent of tumor spread to regional lymph nodes $[8,9]$. In addition, the expression of sonic hedgehog (Shh) and glioma-associated oncogene homolog zinc finger protein 1 (Gli1) has been shown to affect lymphatic metastasis in cancer [10]. In a prior study, the same authors showed that Shh affects the invasion and motility of cancer cells [11].

The Shh signaling pathway has been shown to play a crucial role in the organogenesis of several organs [12] and has been implicated in the regulation of stem-cell fate as well as tissue repair and regeneration $[13,14]$. Shh signaling is activated by binding between Shh and its receptor, Patched (Ptch), which relieves the Ptch-mediated repression of smoothened (Smo), a downstream membrane protein related to $\mathrm{G}$ protein-coupled receptors. Upon activation, Smo promotes the nuclear translocations of a family of transcription factors (Cubitus interruptus (Ci) in Drosophila and Gli1, Gli2 and Gli3 in vertebrates) and subsequently activates target genes through Gli transcription factors [5]. Furthermore, the constitutive activation of the Shh signaling pathway has been reported in various cancers, including basal cell carcinoma prostate, gastrointestinal and lung cancer [15-19].

Researchers in previous studies have suggested that expression of the Shh signaling pathway could affect the prognosis of patients with epithelial cell cancer [20-22]. However, no report has been issued on the relationship between the Shh signaling pathway and prognosis in non-small-cell lung cancer (NSCLC). Accordingly, our objectives in this study were to investigate the relationship between the expression of Shh-associated factors and lymphangiogenic factors and to determine the prognostic roles of these biomarkers in patients with lung cancer.

\section{Methods}

\section{Patients and tissue specimens}

We collected formalin-fixed, paraffin-embedded samples from 40 patients with NSCLC (adenocarcinoma $=15$, squamous cell carcinoma $=20$, mixed type $=2$, bronchioloalveolar carcinoma $=3$ ) who had undergone surgical treatment for NSCLC without neoadjuvant treatment at Korea University Guro Hospital between 2007 and 2009. Permission from the institutional review board of Guro Hospital was obtained beforehand, and informed consent was obtained from all patients (KUGGR-2010-057).

All patients were followed for a median 35.5 months (range $=1$ to 54 months). The sample comprised 30 men and 10 were women with an overall mean age of 62.8 years (range $=44$ to 82 years). Slides were reviewed by two pathologists, and histological type and tumor grade were confirmed according to the 2004 World Health Organization classification of lung cancer. The pathologic tumor and nodal status according to TNM classification were obtained from primary pathology reports. Sixteen $(40.0 \%)$ of the forty patients had stage IA cancer, and eleven $(27.5 \%)$ were in stage IB. Lymph node involvement (above stage IIA) was present in 13 patients (32.5\%).

\section{Immunohistochemistry}

Representative formalin-fixed, paraffin-embedded tissue sections ( $5 \mu \mathrm{m}$ thick) were used for immunohistochemistry. Tissue sections were first deparaffinized in xylene and then rehydrated using an ethanol series. Antigen retrieval was performed using a microwave oven for 20 minutes in $0.01 \mathrm{M}$ citrate buffer ( $\mathrm{pH}$ 6.0), followed by treatment with $0.025 \%$ trypsin in $50 \mathrm{mM}$ Tris buffer for 5 minutes. Endogenous peroxidase activity was blocked using 3\% hydrogen peroxide in phosphate-buffered saline (PBS) for 12 minutes. Sections were then incubated for 1 hour at room temperature in a protein-blocking solution consisting of $\mathrm{PBS}(\mathrm{pH} 7.5)$ containing 5\% normal swine serum and then incubated at $4^{\circ} \mathrm{C}$ overnight with different primary antibodies. The antibodies, sources, clones and dilutions used are listed in Table 1.

Next, the sections were washed three times with distilled water, counterstained with Mayer's hematoxylin (Biogenex Laboratories, San Ramon, CA, USA) and washed with distilled water followed by PBS. Slides were mounted using a universal mounting medium (Dako, Glostrup, Denmark) and examined using a bright-field microscope. Negative controls were prepared in all cases by omitting primary antibodies. The expression levels of Shh, Gli1, LYVE-1 and VEGF-D protein were classified into four groups by staining intensity (intensity scores): 0 (negative), 1 (weak), 2 (moderate) and 3 (strong). The percentages of positive 
Table 1 Antibodies used for immunohistochemical staining $^{a}$

\begin{tabular}{llll}
\hline Antibody & Source & Clone number & Dilution \\
\hline Shh & Abcam & EP1190Y & $1: 200$ \\
Gli1 & Abcam & Polyclonal antibody & $1: 50$ \\
LYVE-1 & Neo-Markers & SPM471 & $1: 30$ \\
VEGF-D & Cell Signaling Technology & Polyclonal antibody & $1: 50$ \\
\hline
\end{tabular}

${ }^{\mathrm{a}}$ Gli1, Glioma-associated oncogene homolog zinc finger protein 1; LYVE-1, Lymphatic vessel endothelial hyaluronan receptor 1; Shh, Sonic hedgehog; VEGF-D, Vascular endothelial growth factor D.

cells were graded (percentage scores) as $0(<5 \%), 1$ (6\% to $15 \%$ ), 2 (16\% to $25 \%$ ), 3 (26\% to $50 \%$ ), 4 (51 to $75 \%$ ) or 5 $(>75 \%)$. Positivity was determined using the following formula: immunohistochemistry score (IHC) = percentage score $\times$ intensity score. An IHC score $>6$ was defined as positive [23] (Figure 1).

\section{Cell lines and reagents}

The human NSCLC cell lines H1299 and Calu-1 were purchased from the Korea Cell Line Bank (KCLB) (Seoul, Korea). Cells were maintained according to instructions provided by the KCLB. Recombinant human Shh Nterminal peptide (N-Shh) was purchased from R\&D
Systems (Minneapolis, MN, USA), and cyclopamineKAAD was purchased from Calbiochem (San Diego, CA, USA).

\section{RT-PCR analysis}

Total RNA extraction was performed using TRIzol reagent (Life Technologies, Rockville, MD, USA) according to the manufacturer's instructions. Transcripts were amplified using $2 \mu \mathrm{g} / \mu \mathrm{l}$ total RNA by RT-PCR using Moloney murine leukemia virus reverse transcriptase (Gibco/Life Technologies, Gaithersburg, MD, USA) and oligo(dT) 15 primer (Roche Molecular Diagnostics, Indianapolis, IN, USA) (Table 2). $\beta$-actin was synthesized by the Bioneer Corporation (Daejeon, Korea). The cycling conditions were $95^{\circ} \mathrm{C}$ for 10 minutes, followed by 30 amplification cycles of $95^{\circ} \mathrm{C}$ for 45 seconds, $60^{\circ} \mathrm{C}$ for 30 seconds and $72^{\circ} \mathrm{C}$ for 30 seconds. Experiments were repeated three times, and the intensities of DNA bands in agarose gel were quantified using ImageJ software (National Institutes of Health, Bethesda, MD, USA).

\section{Small interfering RNA transfection}

siRNA duplex specific to Gli1, Gli2 and Gli3 was synthesized at Invitrogen (Carlsbad, CA, USA) (Table 3). Scrambled siRNA duplex was used as a nonspecific control siRNA. Transfection was performed using Lipofectamine
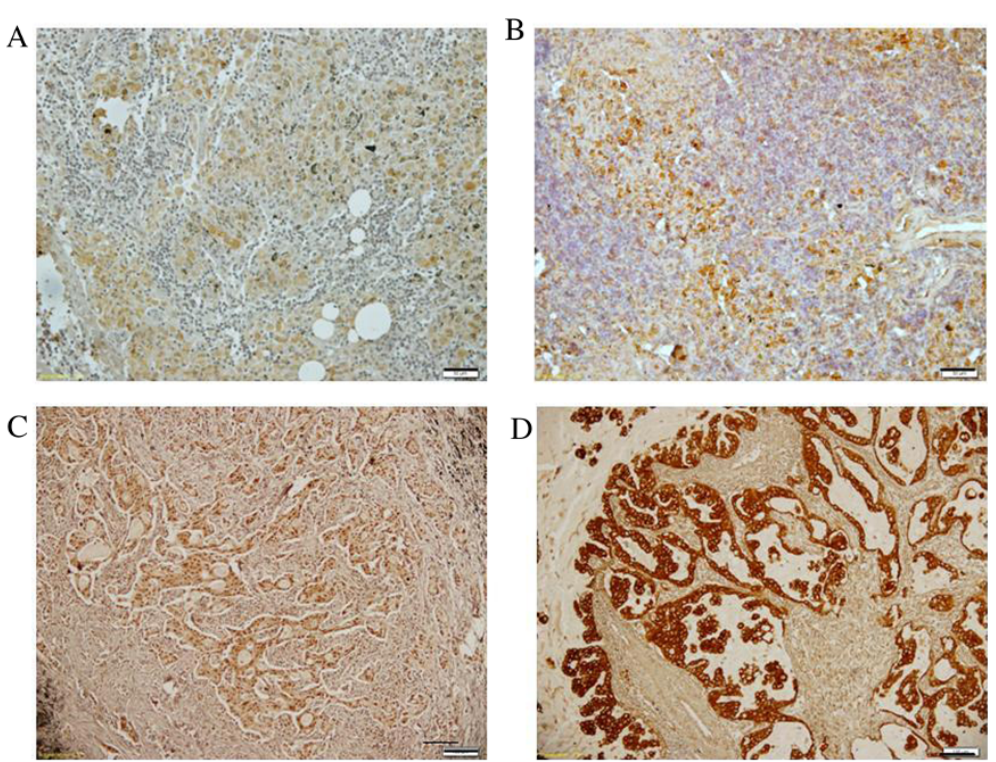

Figure 1 Activation of the Shh signaling pathway and lymphangiogenesis in non-small-cell lung cancer. Immunohistochemical staining was performed on tumor tissues obtained from 40 non-small-cell lung cancer (NSCLC) patients for the Sonic hedgehog (Shh) signaling pathway (Shh, glioma-associated oncogene homolog zinc finger protein 1 (Gli1)) and lymphangiogenic factors (vascular endothelial growth factor D (VEGF-D), lymphatic vessel endothelial hyaluronan receptor 1 (LYVE-1)) using appropriate antibodies. Immunohistochemistry scores (IHC scores) were calculated from positive staining area percentages and intensity scores. Staining intensity scores were graded as follows: $0=$ negative (A), $1=$ weak (B), $2=$ moderate $(\mathbf{C})$ and $3=$ strong (D). Scale bar $=50 \mu \mathrm{m}$. Positive area percentages were graded as follows: grade $0(\leq 5 \%), 1(6 \%$ to $15 \%), 2(16 \%$ to $25 \%), 3(26 \%$ to $50 \%), 4(51 \%$ to $75 \%)$ and 5 (>75\%). Positivity was determined using the following formula: $1 \mathrm{HC}$ score $=$ percentage score $\times$ staining intensity score. Positive expression was defined as an IHC score $>6$. 
Table 2 Primer sequences used for RT-PCR

\begin{tabular}{lll}
\hline & Primers 5'-3' & \\
\hline RNA & Forward & Reverse \\
LYVE-1 & CCA GTG AGC CGA CAG & CAG GTA TTG TAG AGT AAG \\
& TाT GGA G & GGG ATG CC \\
VEGF-D & CAG TGA AGC GAT CAT & TAC GAG GTG CTG GTG TTC \\
& CTC AG & ATA C \\
Gli1 & TGC CT GTA CCC TCC & GCG ATC TGT GAT GGA TGA \\
& TCC CGA A & GAT TCC C \\
Gli2 & AGA TTC TGA GCC AGC & TGG TGT CAC TCA GAC AGT \\
& AGA GG & TGC \\
Gli3 & TGC AGG GTG AAT GGT & TGA TTA GCA CCT GGG GAA \\
& ATC AA & AG \\
B-actin & ACC CAG ATC ATG TT & GGA GTT GAA GGT AGT TTC \\
& GAG AC & GT
\end{tabular}

${ }^{\mathrm{a}}$ Gli1, Glioma-associated oncogene homolog zinc finger protein 1; LYVE-1, Lymphatic vessel endothelial hyaluronan receptor 1; Shh, Sonic hedgehog; VEGF-D, Vascular endothelial growth factor D.

RNAiMAX reagent (Invitrogen), according to the manufacturer's instructions.

\section{Cell proliferation assay}

Gli1, Gli2 and Gli3 siRNA transfected cells were seeded at a concentration of $4 \times 10^{3}$ cells per $100 \mu$ l of culture medium per well in 96-well plates. After 24 or 48 hours, viable cells were counted in triplicate wells using a 3(4,5-dimethylthiazol-2-yl)-2,5-diphenyltetrazolium bromide (MTT) assay (Roche Molecular Diagnostics) according to the manufacturer's instructions.

\section{Statistical analysis}

Fisher's exact test was used to evaluate associations between protein expression and clinical parameters (when two independent groups were compared). The KaplanMeier method was used to plot survival curves, and a logrank test was used to compare survival. Multivariate analysis was performed using the Cox proportional hazards model to determine the significance of relationships between variables and survival. SPSS version 15.0 for Windows software (IBM SPSS, Chicago, IL, USA) was

Table 3 Transfected siRNA sequences ${ }^{a}$

\begin{tabular}{ll}
\hline siRnA & Sequences \\
\hline Gli1 & 5'-AUA UCU UGC CCG AAG CAG GUA GUG C-3' \\
& 5'-GCA CUA CCU GCU UCG GGC AAG AUA U-3' \\
& 5'-CAU AGA UGA CCA CCU CAG CCU CCU G-3' \\
Gli2 & 5'-CAG GAG GCU GAG GUG GUC AUC UAU G-3' \\
& 5'-UUC AGU CGC GGA AAC AUU CCA UUC A-3' \\
Gli3 & 5'-UGA AUG GAA UGU UUC CGC GAC UGA A-3' \\
\hline
\end{tabular}

${ }^{\mathrm{a}}$ Gli1, Glioma-associated oncogene homolog zinc finger protein 1; LYVE-1, Lymphatic vessel endothelial hyaluronan receptor 1 ; Shh, Sonic hedgehog; VEGF-D, Vascular endothelial growth factor D. used for statistical analysis, and statistical significance was accepted for $P$-values $<0.05$.

\section{Results}

Immunohistochemistry of Shh, Gli1, LYVE-1 and VEGF-D in non-small-cell lung cancer

Shh expression was positive in 25 (62.5\%) of the 40 NSCLC specimens, and Gli1, LYVE-1 and VEGF-D were positive in 20 (50.0\%), $11(27.5 \%)$ and $20(50.0 \%)$ of the 40 specimens, respectively. Normal potions of NSCLC tissues and negative controls were negative for Shh, Gli1, LYVE-1 and VEGF-D (Figure 1).

\section{Relationships between Shh, Gli 1, LYVE-1 and VEGF-D}

The expression of Gli1 and LYVE-1 was correlated ( $r=$ $0.579, P<0.05$ ) (Table 4). In addition, the expression of Shh, Gli1, LYVE-1 and VEGF-D proteins was found to be related with some clinicopathological factors (Table 5). In particular, Shh was significantly highly expressed in cases of visceral pleural invasion $(P=0.01)$, and Gli was significantly and highly expressed in squamous cell histology $(P=0.048)$. LYVE-1 (the lymphangiogenic factor) was highly expressed in cases of lymphatic thromboembolisms $(P=0.001)$. However, Shh and Gli expression were not found to be related with any strong prognostic factor, such as TNM stage, tumor recurrence or distant metastasis. Furthermore, lymphangiogenic factors LYVE1 and VEGF-D showed no relation with T stage, $\mathrm{N}$ stage, tumor recurrence or distant metastasis.

\section{Sonic hedgehog-mediated non-small-cell lung cancer cell} line proliferation in vitro

To investigate the role of the Shh signaling pathway in the cell proliferation of NSCLC cell lines, we used an MTT assay to examine the effects of Shh on cell proliferation after inhibiting the Shh signaling pathway in H1299 and H2009 cells. As shown in Figure 2A, cyclopamineKADD (a Smo inhibitor) inhibited the cell growth of both NSCLC cell lines. Gli1, Gli2 and Gli3 siRNA transfectants reduced the proliferation of cells. After 24 and 48 hours, H1299 and Calu-1 cells showed inhibited cell growth versus control siRNA transfected cells (Figures 2 and 3).

Table 4 Correlation analysis ${ }^{a}$

\begin{tabular}{lllll}
\hline Variable & $\begin{array}{l}\text { Shh } \\
\text { expression }\end{array}$ & $\begin{array}{l}\text { Gli1 } \\
\text { expression }\end{array}$ & $\begin{array}{l}\text { LYVE-1 } \\
\text { expression }\end{array}$ & $\begin{array}{l}\text { VEGF-D } \\
\text { expression }\end{array}$ \\
\hline Shh expression & 1 & & & \\
Gli1 expression & -0.281 & 1 & & \\
LYVE-1 expression & -0.084 & $0.579^{*}$ & 1 & 1 \\
VEGF-D expression & -0.198 & 0.169 & 0.096 & 1
\end{tabular}

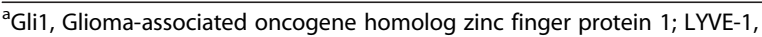
Lymphatic vessel endothelial hyaluronan receptor 1; Shh, Sonic hedgehog; VEGF-D, Vascular endothelial growth factor $D$. ${ }^{*} P<0.05$. 
Table 5 Relationship between the protein expression of Shh, Gli1, LYVE-1 and VEGF-D and non-small-cell lung cancer ${ }^{a}$

\begin{tabular}{|c|c|c|c|c|c|c|c|c|c|c|c|c|}
\hline \multirow{2}{*}{$\begin{array}{l}\text { Clinicopathological } \\
\text { features }\end{array}$} & \multicolumn{3}{|c|}{ Shh expression } & \multicolumn{3}{|c|}{ Gli1 expression } & \multicolumn{3}{|c|}{ LYVE-1 expression } & \multicolumn{3}{|c|}{ VEGF-D expression } \\
\hline & Negative & Positive & $P$ & Negative & Positive & $P$ & Negative & Positive & $P$ & Negative & Positive & $P$ \\
\hline \multicolumn{13}{|l|}{ Age, yr } \\
\hline$<65$ & 11 & 12 & 0.117 & 11 & 12 & 0.749 & 18 & 5 & 0.477 & 14 & 9 & 0.11 \\
\hline$\geq 65$ & 4 & 13 & & 9 & 8 & & 11 & 6 & & 6 & 11 & \\
\hline \multicolumn{13}{|l|}{ Gender } \\
\hline Female & 4 & 6 & 1.00 & 5 & 5 & 1 & 6 & 4 & 0.418 & 5 & 5 & 1.00 \\
\hline Male & 11 & 19 & & 15 & 15 & & 23 & 7 & & 15 & 15 & \\
\hline \multicolumn{13}{|l|}{ Histology } \\
\hline Nonsquamous & 8 & 12 & 0.744 & 14 & 6 & $0.048^{\dagger}$ & 15 & 5 & 0.723 & 10 & 10 & 1.00 \\
\hline Squamous & 7 & 13 & & 6 & 14 & & 14 & 6 & & 10 & 10 & \\
\hline \multicolumn{13}{|l|}{ Tumor size } \\
\hline$<3 \mathrm{~cm}$ & 11 & 14 & 0.273 & 12 & 13 & 0.744 & 19 & 6 & 0.716 & 13 & 12 & 0.744 \\
\hline$\geq 3 \mathrm{~cm}$ & 4 & 11 & & 8 & 7 & & 10 & 5 & & 7 & 8 & \\
\hline \multicolumn{13}{|l|}{ Node stage } \\
\hline 0 & 9 & 18 & 0.498 & 12 & 15 & 0.311 & 21 & 6 & 0.451 & 14 & 13 & 0.736 \\
\hline 1 to 2 & 6 & 7 & & 8 & 5 & & 8 & 5 & & 6 & 7 & \\
\hline \multicolumn{13}{|l|}{ VPI } \\
\hline No & 13 & 11 & $0.01^{\dagger}$ & 12 & 12 & 1.00 & 17 & 7 & 1.00 & 12 & 12 & 1.00 \\
\hline Yes & 2 & 14 & & 8 & 8 & & 12 & 4 & & 8 & 8 & \\
\hline \multicolumn{13}{|l|}{ LTE } \\
\hline No & 13 & 22 & 1.00 & 17 & 18 & 1.00 & 29 & 6 & $0.001^{\dagger}$ & 18 & 17 & 1.00 \\
\hline Yes & 2 & 3 & & 3 & 2 & & 0 & 5 & & 2 & 3 & \\
\hline \multicolumn{13}{|l|}{ Smoking history } \\
\hline No & 7 & 12 & 0.935 & 10 & 9 & 0.752 & 13 & 6 & 0.583 & 10 & 9 & 0.752 \\
\hline Yes & 8 & 13 & & 10 & 11 & & 16 & 5 & & 10 & 11 & \\
\hline \multicolumn{13}{|l|}{ Tumor recurrence } \\
\hline No & 11 & 18 & 1.00 & 13 & 16 & 0.288 & 22 & 7 & 0.455 & 14 & 15 & 0.723 \\
\hline Yes & 4 & 7 & & 7 & 4 & & 7 & 4 & & 6 & 5 & \\
\hline \multicolumn{13}{|l|}{ Distant metastasis } \\
\hline No & 14 & 23 & 1.00 & 19 & 18 & 1.00 & 27 & 10 & 1.00 & 19 & 18 & 1.00 \\
\hline Yes & 1 & 2 & & 1 & 2 & & 2 & 1 & & 1 & 2 & \\
\hline
\end{tabular}

${ }^{a}$ Gli1, Glioma-associated oncogene homolog zinc finger protein 1; LTE, Lymphatic thromboembolism; LYVE-1, Lymphatic vessel endothelial hyaluronan receptor 1 ; Shh, Sonic hedgehog; VEGF-D, Vascular endothelial growth factor D; VPI, Visceral pleura invasion. P-values were calculated using Fisher's exact test. ${ }^{\dagger} P<0.05$.

These observations confirm that inhibition of the Shh signaling pathway regulates the viability of NSCLC cell lines.

Sonic hedgehog signaling pathway and lymphangiogenesis of non-small-cell lung cancer cell lines in vitro

To confirm the contribution made by the Shh signaling pathway to the expression of lymphangiogenic factors in NSCLC, cells were treated with N-Shh peptide or KADDcyclopamine. Those cells were treated with N-Shh. RT-PCR analysis showed that the mRNA expression of LYVE-1 and VEGF-D in H1299 and Calu-1 cells was induced after 30 minutes of N-Shh stimulation (Figure 3A). However, the blockade of Shh signaling by cyclopamine completely prevented these increases in mRNA expression of LYVE-1 and VEGF-D (Figure 3B). Together, these results show that lymphangiogenic factors are regulated by the Shh signaling pathway.

\section{Survival analysis}

In the Kaplan-Meier survival analysis, overall 3-year survival was $83.6 \%$. Median survival could not be calculated, because 7 of 40 patients died and 9 were lost to follow-up during the period. We also analyzed relationships between patient survival (all 40 had undergone curative resection) and the expression of Shh, Gli1, LYVE-1 and VEGF-D. Survival curves were plotted for those positive or 

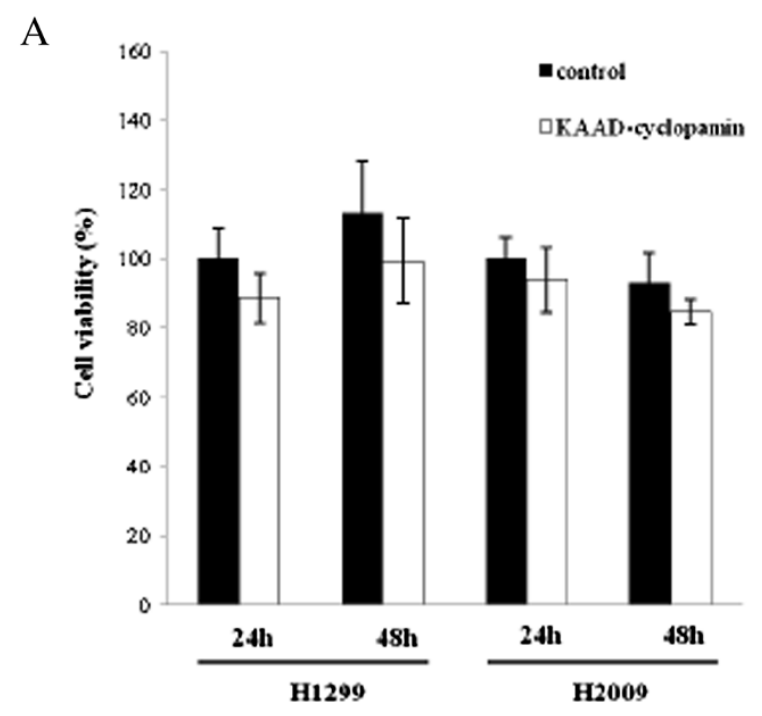

B

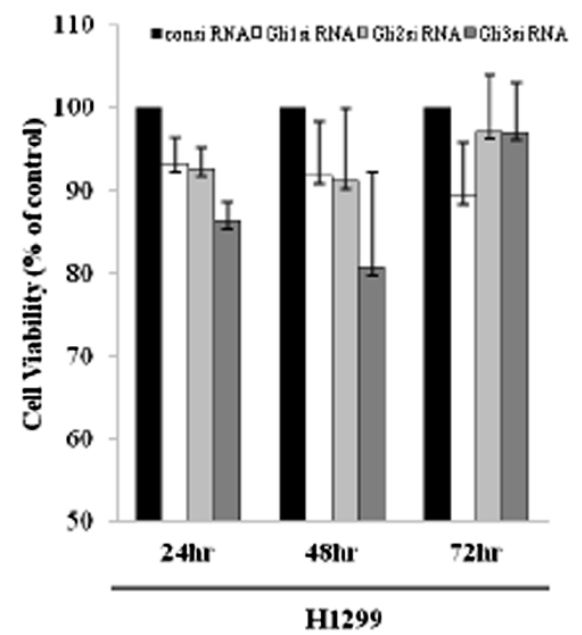

$\mathrm{C}$

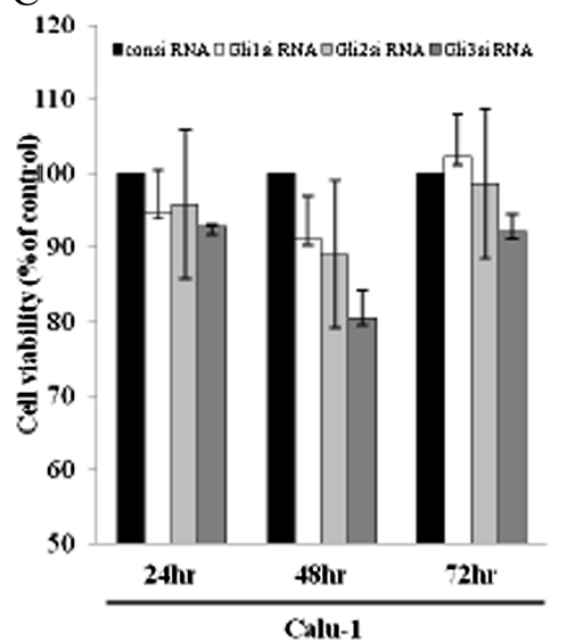

$\mathrm{D}$

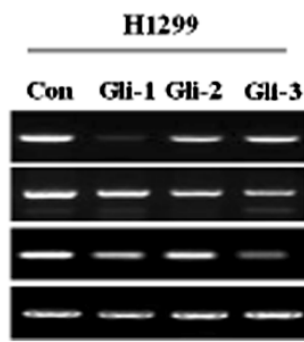

Calu-1

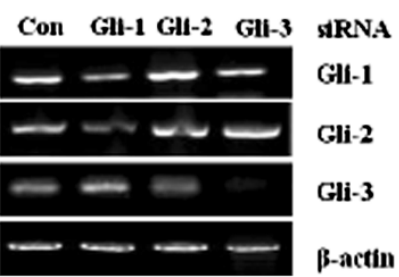

Figure 2 Sonic hedgehog signaling and non-small-cell lung cancer cell proliferation. 3-(4,5-dimethylthiazol-2-yl)-2,5-diphenyltetrazolium bromide viability assays were performed to measure cell proliferation. (A) Proliferation of $\mathrm{H} 1299$ and $\mathrm{H} 2009$ cells treated with cyclopamine-KAAD $(10$ MM). (B) and (C) Proliferation of H1299 and Calu-1 cells transfected with Gli1, Gli2 or Gli3 siRNA or nonspecific control (Con) siRNA. Bars represent the standard deviations of three independent experiments conducted in triplicate. (D) H1299 and Calu-1 cells were transfected with Gli1, Gli2 or Gli3 siRNA or nonspecific control siRNA and harvested 48 hours later. RT-PCR was performed for endogenous Gli1, Gli2 and Gli3 transcripts. $\beta$-actin was used as a loading control.

negative for Shh expression (Figure 4). We found that survival of patients whose Shh expression was positive was significantly lower than patients whose Shh expression was negative. ( $P=0.020$ by logrank analysis). In survival curve analysis of Gli1 expession, there was no statistical significance ( $P=0.55$ by logrank analysis). 


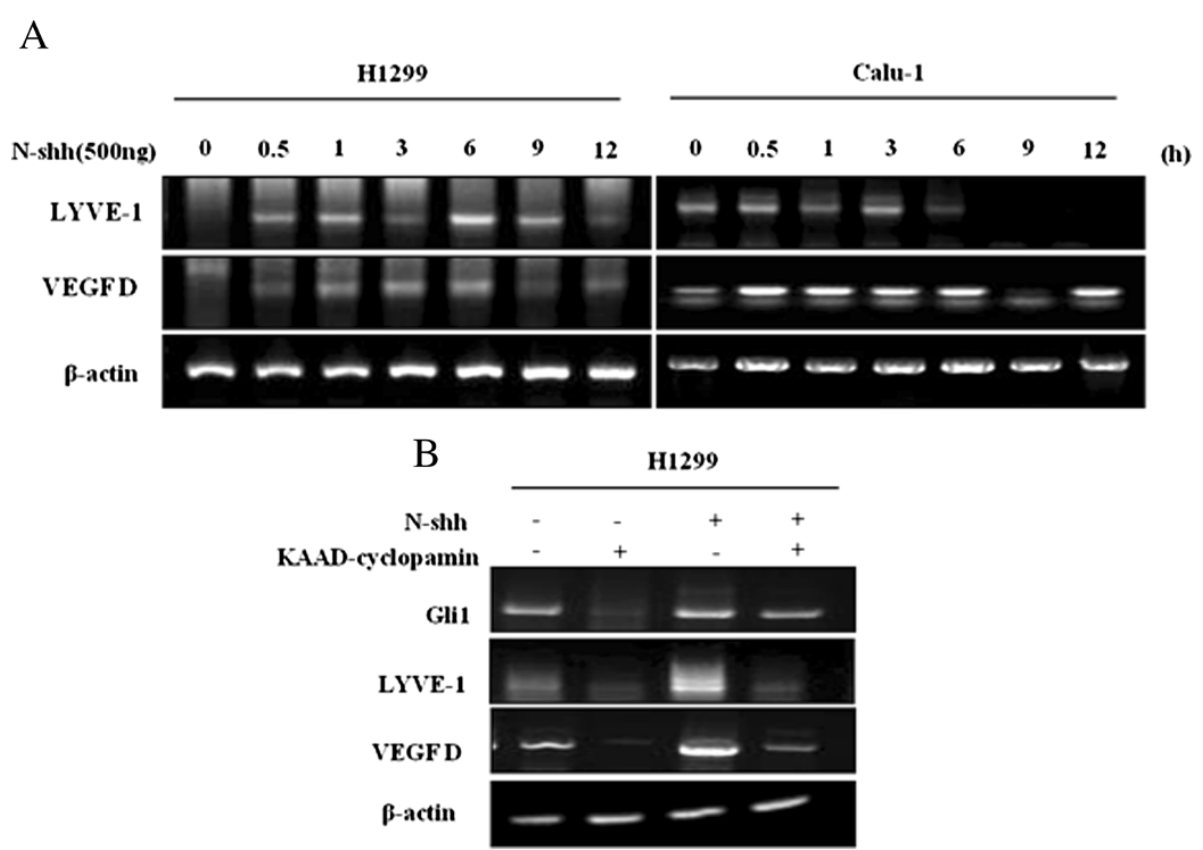

Figure 3 The sonic hedgehog signaling pathway was regulated by lymphangiogenic factors. (A) H1299 and Calu-1 cells were treated with $500 \mathrm{ng} / \mathrm{ml} \mathrm{N}$-Shh for the indicated times. The total RNA was harvested and subjected to RT-PCR using lymphatic vessel endothelial hyaluronan receptor 1 (LYVE-1), vascular endothelial growth factor D (VEGF-D) or $\beta$-actin (loading control) primers. (B) H1299 cells were treated with 500 ng of N-Shh or $10 \mu \mathrm{M}$ cyclopamine-KAAD for 24 hours, and RNAs were isolated and subjected to RT-PCR for Glioma-associated oncogene homolog zinc finger protein 1 (Gli1), LYVE-1, VEGF-D or $\beta$-actin (loading control).

However, these indicated that the Shh pathway may be related to survival of non-small-cell lung cancer.Univariate analysis revealed that Shh and Gli had significant effects on survival, but multivariate Cox regression analyses failed to identify a factor significantly associated with survival (Table 6).

Interestingly, we found LYVE-1 to be associated with lymphatic thromboembolism (Table 5), which is believed to represent the starting point of lymphovascular invasion. However, LYVE-1 was not found to be associated with lymph node invasion or distant metastasis.

\section{Discussion}

The results of the present study show that Shh and Gl-1 are more highly expressed in NSCLC tissues than in normal counterpart tissues.Gli1 protein was detected mainly in tumor tissues, but occasionally in nontumor tissues. These results suggest that the Shh pathway activates NSCLC carcinogenesis, as has been shown for other cancers. The role played by the Shh pathway in lung cancer carcinogenesis has not been fully elucidated, but, in line with other studies on this topic [24,25], our results demonstrate that the Shh pathway is highly expressed in NSCLC tissues. Raz et al. demonstrated that Shh pathway components, such as Shh, Smo and Gli, are strongly related to adenocarcinoma histological cell type in lung cancer, whereas in the present study Gli was strongly expressed in squamous lung cancer. More study of this topic is required.

To our knowledge, this study is the first to show Shh signaling/lymphangiogenic pathway crosstalk in human lung cancer tissues. Furthermore, we found significant relationships between the expression of component of the Shh (Gli1) and lymphangiogenesis (LYVE-1) pathways. Accordingly, the results of this study suggest that the Shh pathway may have a role in lymphangiogenesis.

Asai et al. demonstrated that activation of the Shh pathway promotes wound-healing and induces angiogenesisrelated events, such as endothelial progenitor cell proliferation, migration, adhesion and tube formation [26]. Bailey et al. demonstrated that Shh-neutralizing antibody decreased the number of LYVE-1-positive cells in a mouse model of pancreatic cancer [27]. In our previous study, we demonstrated that the Shh signaling pathway, through the phospho-AKT pathway, enhanced intratumoral lymphatic invasion in gastric cancer [11]. Taken together, these results suggest that the Shh pathway may play a role in the lymphangiogenesis of lung cancer.

We did not find a direct relationship between Shh and lymph node involvement, possibly because of the small number of patients recruited or because Shh affects only the early stage of intratumoral lymphangiogenesis 


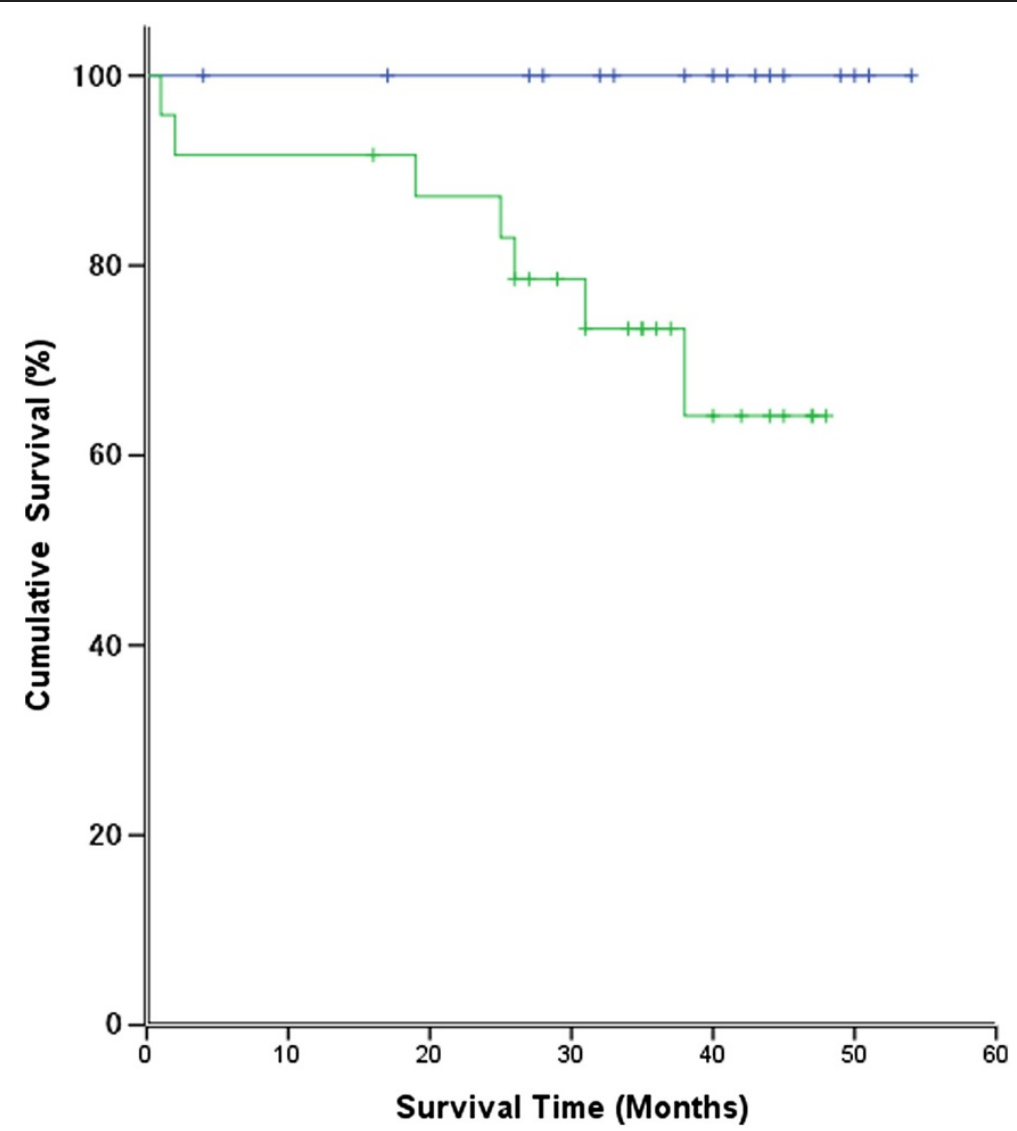

Figure 4 Overall survival curves for $\mathbf{4 0}$ non-small-cell lung cancer patients positive or negative for sonic hedgehog expression. Survival was analyzed using the Kaplan-Meier method, and survival differences between the positive and negative groups were compared using a logrank test. Patients with a tumor positive for Shh were found to have significantly poorer survival $(P=0.020)$.

and not lymph node metastasis, which requires the collaborative activities of several systems, such as the epithelial-to-mesenchymal transition and matrix metalloproteinase systems.

Nonetheless, this study shows a strong relationship between LYVE-1 expression and lymphatic thromboembolism, which is considered the first stage of lymph node metastasis. However, the relationship between Shh and lymph node metastasis requires further study.

In the present study, Shh overexpression was found to be associated with the occurrence of visceral pleural invasion. However, the mechanism and underlying significance of this visceral involvement was not determined. Nevertheless, several authors have suggested that activation of the Shh signaling pathway might promote tumor metastasis, and our results are compatible with this suggestion $[10,11,27]$.

To our knowledge, we are the first to report that the Shh signaling pathway affects survival in lung cancer. Our results show that expression of the Shh pathway was not affected by TNM stage, tumor recurrence or distant metastasis. Furthermore, despite weak associations between well-known prognostic factors, Shh and Gli expression were found to be associated with survival, which suggests that Shh and Gli expression may have prognostic value independent of TNM staging with respect to the future development of recurrence and distant metastasis. However, we should be cautious about interpreting these results because of the possibility of population selection bias. To avoid this limitation, we selected candidates for surgical resection, but our results should be validated in a larger cohort. To define the mechanism responsible for the survival disadvantage conferred by Shh pathway activation in lung cancer, we examined whether Shh pathway inhibition affects lung cancer cell survival. We found that treatment with siRNA Gli inhibited proliferation of the H1299 and Calu-1 lung cancer cell lines. We tentatively suggest that the poor prognosis of patients with tumors showing high Shh expression is probably due to the induction of proliferation and the activation of lymphangiogenesis.

The significance of the clinicopathological heterogeneity displayed by cancers of the same stage is difficult to understand. Some early-stage lung cancer patients experience 
Table 6 Univariate and multivariate analyses of prognostic factors in non-small-cell lung cancer ${ }^{a}$

\begin{tabular}{|c|c|c|}
\hline \multirow[b]{2}{*}{ Clinicopathological parameter } & \multicolumn{2}{|l|}{$P$-value } \\
\hline & $\begin{array}{l}\text { Univariate } \\
\text { analysis }^{\mathrm{b}}\end{array}$ & $\begin{array}{l}\text { Multivariate } \\
\text { analysis }^{c}\end{array}$ \\
\hline Tumor size, $<3 \mathrm{~cm} />3 \mathrm{~cm}$ & 0.885 & 0.108 \\
\hline Visceral pleural invasion, negative/positive & 0.357 & 0.528 \\
\hline Lymph node metastasis, negative/positive & 0.495 & 0.542 \\
\hline $\begin{array}{l}\text { Lymphatic thromboembolism, negative/ } \\
\text { positive }\end{array}$ & 0.976 & 0.997 \\
\hline Tumor recurrence, negative/positive & 0.34 & 0.959 \\
\hline Distant metastasis, negative/positive & 0.591 & 0.949 \\
\hline Shh expression, negative/positive & $0.02^{d}$ & 0.959 \\
\hline Gli1 expression, negative/positive & 0.055 & 0.953 \\
\hline LYVE-1 expression, negative/positive & 0.323 & 0.965 \\
\hline VEGFD expression, negative/positive & 0.857 & 0.703 \\
\hline
\end{tabular}

${ }^{\mathrm{a}} \mathrm{Gli1}$, Glioma-associated oncogene homolog zinc finger protein 1; LYVE-1, Lymphatic vessel endothelial hyaluronan receptor 1; Shh, Sonic hedgehog; VEGF-D, Vascular endothelial growth factor D. ${ }^{b}$ Logrank test; ${ }^{\circ}$ Cox regression model; ${ }^{\mathrm{d}} P<0.05$

recurrence despite complete resection and postoperative adjuvant chemotherapy, whereas others do not. This implies that an understanding of the molecular basis of lung cancer is needed to identify molecular targets for drug development purposes.

In a preclinical study, it was demonstrated that hedgehog inhibitor can have a cytotoxic effect on cancer cells [28]. Recently, it was suggested that the Shh pathway might be involved in drug and radiotherapy resistance in lung cancer [29]. More specifically, it was found that hedgehog pathway inhibitor increases the efficacy of radiotherapy by affecting stromal cells surrounding cancer tissues. The Shh pathway is a key player in embryonal organogenesis and could be a marker for cancer stem cells [30]. Chemo- and radioresistance are characteristic of cancer stem cells. To overcome this resistance, a comprehensive understanding of cancer stem cell markers is needed, because, despite the improved results realized with modern chemotherapeutic and target agents, the outcome of lung cancer remains dismal. Because cure is the final goal of cancer treatment, a new treatment modality that targets cancer stem cells is urgently needed.

\section{Conclusions}

The results of this study show that the Shh signaling pathway affects survival in lung cancer and suggest that Shh initiates lymph node metastasis via LYVE-1dependent lymphangiogenesis. These findings strongly suggest that the Shh pathway plays an important role in NSCLC progression and that this pathway should be considered a potential therapeutic target. However, somewhat surprisingly, an advanced stage was not found to influence survival, which we attribute to the size of our cohort. Nevertheless, despite the proportion of our cohort that did not have a strong association of survival with well-known prognostic factors such as tumor stage, lymph node stage, tumor recurrence and distant metastasis, the Shh pathway molecule did show a significant difference in survival rate. Further investigations are needed to clarify the role of the Shh signaling pathway and the underlying mechanisms responsible for driving the malignant behavior of NSCLC.

\section{Abbreviations \\ Gli: Glioma-associated oncogene homolog zinc finger protein; IHC: Immunohistochemistry; LYVE-1: Lymphatic vessel endothelial hyaluronan receptor 1; MTT: 3-(4,5-dimethylthiazol-2-yl)-2,5-diphenyltetrazolium bromide; NSCLC: Non-small-cell lung cancer; PBS: Phosphate-buffered saline; Ptch: Patched; Shh: Sonic hedgehog; Smo: Smoothened; VEGF-D: Vascular endothelial growth factor D. \\ Competing interests \\ The authors declare that they have no competing interests. \\ Authors' contributions \\ HKK and SCO carried out the study conception and design. JH and MHK were equally responsible for data collecting and manuscript writing. YAY, YHQ and YHC participated in the design of the study and performed the statistical analysis. All authors read and approved the final manuscript.}

\section{Acknowledgements}

This research was supported by the Basic Science Research Program of the Korean National Research Foundation (NRF), funded by the Korean Ministry of Education, Science, and Technology (grant 20120003904).

\section{Author details}

'Department of Thoracic and Cardiovascular Surgery, Korea University Ansan Hospital, Korea University College of Medicine, 123 Jeokgeum-ro, Danwon-gu, Ansan, Gyeonggi-do 425-707, Republic of Korea. ${ }^{2}$ Division of Oncology/Hematology, Departments of Internal Medicine, Korea University Guro Hospital, Korea University College of Medicine, 97 Guro-dong kil, Guro-ku, Seoul 152-703, Republic of Korea. ${ }^{3}$ Department of Thoracic and Cardiovascular Surgery, Korea University Guro Hospital, Korea University College of Medicine, 97 Guro-dong kil, Guro-ku, Seoul 152-703, Republic of Korea.

Received: 22 March 2014 Accepted: 6 August 2014

Published: 21 August 2014

\section{References}

1. Jemal A, Siegel R, Xu J, Ward E: Cancer statistics, 2010. CA Cancer J Clin 2010, 60:277-300. A published erratum appears in CA Cancer J Clin 2011, 61:133-1344.

2. Siegel R, Naishadham D, Jemal A: Cancer statistics, 2013. CA Cancer J Clin 2013, 63:11-30

3. Tyczynski JE, Bray F, Parkin DM: Lung cancer in Europe in 2000: epidemiology, prevention, and early detection. Lancet Oncol 2003, 4:45-55.

4. Miller YE: Pathogenesis of lung cancer: 100 year report. Am J Respir Cell Mol Biol 2005, 33:216-223.

5. Rusch WW, Asamura H, Watanabe H, Giroux DJ, Rami-Porta R, Goldstraw P, Members of the IASLC Staging Committee: The IASLC lung cancer staging project: a proposal for a new international lymph node map in the forthcoming seventh edition of the TNM classification for lung cancer. J Thorac Oncol 2009, 4:568-577.

6. De Leyn P, Lardinois D, Van Schil PE, Rami-Porta R, Passlick B, Zielinski M, Waller DA, Lerut T, Weder W: ESTS guidelines for preoperative lymph 
node staging for non-small cell lung cancer. Eur J Cardiothorac Surg 2007, $32: 1-8$.

7. Martinez-Corral I, Makinen T: Regulation of lymphatic vascular morphogenesis: implications for pathological (tumor) lymphangiogenesis. Exp Cell Res 2013, 319:1618-1625.

8. Skobe M, Hawighorst T, Jackson DG, Prevo R, Janes L, Velasco P, Riccardi L, Alitalo K, Claffey K, Detmar M: Induction of tumor lymphangiogenesis by VEGF-C promotes breast cancer metastasis. Nat Med 2001, 7:192-198.

9. Stacker SA, Caesar C, Baldwin ME, Thornton GE, Williams RA, Prevo R, Jackson DG, Nishikawa S, Kubo H, Achen MG: VEGF-D promotes the metastatic spread of tumor cells via the lymphatics. Nat Med 2001, 7:186-191.

10. Mori Y, Okumura T, Tsunoda S, Sakai Y, Shimada Y: Gli-1 expression is associated with lymph node metastasis and tumor progression in esophageal squamous cell carcinoma. Oncology 2006, 70:378-389.

11. Yoo YA, Kang MH, Lee HJ, Kim BH, Park JK, Kim HK, Kim JS, Oh SC: Sonic hedgehog pathway promotes metastasis and lymphangiogenesis via activation of Akt, EMT, and MMP-9 pathway in gastric cancer. Cancer Res 2011, 71:7061-7070.

12. van Tuyl M, Post M: From fruitflies to mammals: mechanisms of signalling via the Sonic hedgehog pathway in lung development. Respir Res 2000, 1:30-35.

13. Katoh $Y$, Katoh M: Hedgehog signaling pathway and gastrointestinal stem cell signaling network (review). Int J Mol Med 2006, 18:1019-1023.

14. Ruiz I, Altaba A, Stecca B, Sánchez P: Hedgehog-Gli signaling in brain tumors: stem cells and paradevelopmental programs in cancer. Cancer Lett 2004, 204:145-157.

15. Daya-Grosjean L, Couvé-Privat S: Sonic hedgehog signaling in basal cell carcinomas. Cancer Lett 2005, 225:181-192.

16. Sheng T, Li C, Zhang X, Chi S, He N, Chen K, McCormick F, Gatalica Z, Xie J: Activation of the hedgehog pathway in advanced prostate cancer. Mol Cancer 2004, 3:29.

17. Karhadkar SS, Bova GS, Abdallah N, Dhara S, Gardner D, Maitra A, Isaacs JT, Berman DM, Beachy PA: Hedgehog signalling in prostate regeneration, neoplasia and metastasis. Nature 2004, 431:707-712.

18. Ma X, Chen K, Huang S, Zhang X, Adegboyega PA, Evers BM, Zhang H Xie J: Frequent activation of the hedgehog pathway in advanced gastric adenocarcinomas. Carcinogenesis 2005, 26:1698-1705.

19. Velcheti V, Govindan R: Hedgehog signaling pathway and lung cancer. J Thorac Oncol 2007, 2:7-10.

20. Wang YF, Chang CJ, Lin CP, Chang SY, Chu PY, Tai SK, Li WY, Chao KS, Chen $\mathrm{YJ}$ : Expression of hedgehog signaling molecules as a prognostic indicator of oral squamous cell carcinoma. Head Neck 2012, 34:1556-1561.

21. Li Q, Zhang Y, Zhan H, Yuan Z, Lu P, Zhan L, Xu W: The Hedgehog signalling pathway and its prognostic impact in human gliomas. ANZ J Surg 2011, 81:440-445.

22. He HC, Chen JH, Chen XB, Qin GQ, Cai C, Liang YX, Han ZD, Dai QS, Chen YR, Zeng GH, Zhu JG, Jiang FN, Zhong WD: Expression of hedgehog pathway components is associated with bladder cancer progression and clinical outcome. Pathol Oncol Res 2012, 18:349-355.

23. Taylor CR: Quantifiable internal reference standards for immunohistochemistry: the measurement of quantity by weight. Appl Immunohistochem Mol Morphol 2006, 14:253-259.

24. Raz G, Allen KE, Kingsley C, Cherni I, Arora S, Watanabe A, Lorenzo CD, Edwards VD, Sridhar S, Hostetter G, Weiss GJ: Hedgehog signaling pathway molecules and ALDH1A1 expression in early-stage non-small cell lung cancer. Lung Cancer 2012, 76:191-196.

25. Savani M, Guo Y, Carbone DP, Csiki I: Sonic hedgehog pathway expression in non-small cell lung cancer. Ther Adv Med Oncol 2012, 4:225-233.

26. Asai J, Takenaka H, Kusano KF, li M, Luedemann C, Curry C, Eaton E, I wakura A, Tsutsumi Y, Hamada H, Kishimoto S, Thorne T, Kishore R, Losordo DW: Topical sonic hedgehog gene therapy accelerates wound healing in diabetes by enhancing endothelial progenitor cell-mediated microvascular remodeling. Circulation 2006, 113:2413-2424.

27. Bailey JM, Mohr AM, Hollingsworth MA: Sonic hedgehog paracrine signaling regulates metastasis and lymphangiogenesis in pancreatic cancer. Oncogene 2009, 28:3513-3525.

28. Singh S, Wang Z, Liang Fei D, Black KE, Goetz JA, Tokhunts R, Giambelli C, Rodriguez-Blanco J, Long J, Lee E, Briegel KJ, Bejarano PA, Dmitrovsky E, Capobianco AJ, Robbins DJ: Hedgehog-producing cancer cells respond to and require autocrine Hedgehog activity. Cancer Res 2011, 71:4454-4463.
29. Zeng J, Aziz K, Chettiar ST, Aftab BT, Armour M, Gajula R, Gandhi N, Salih T, Herman JM, Wong J, Rudin CM, Tran PT, Hales RK: Hedgehog pathway inhibition radiosensitizes non-small cell lung cancers. Int J Radiat Oncol Biol Phys 2013, 86:143-149.

30. Milla LA, González-Ramírez CN, Palma V: Sonic hedgehog in cancer stem cells: a novel link with autophagy. Biol Res 2012, 45:223-230.

doi:10.1186/1477-7819-12-268

Cite this article as: Hwang et al:: The effects of sonic hedgehog signaling pathway components on non-small-cell lung cancer progression and clinical outcome. World Journal of Surgical Oncology 2014 12:268.

\section{Submit your next manuscript to BioMed Central and take full advantage of:}

- Convenient online submission

- Thorough peer review

- No space constraints or color figure charges

- Immediate publication on acceptance

- Inclusion in PubMed, CAS, Scopus and Google Scholar

- Research which is freely available for redistribution 